\title{
Multidrug Resistant Enteric Bacterial Pathogens in a Psychiatric Hospital in Ghana: Implications for Control of Nosocomial Infections
}

\author{
Kwabena O. Duedu, ${ }^{1}$ George Offei, ${ }^{2}$ Francis S. Codjoe, ${ }^{2}$ and Eric S. Donkor ${ }^{3}$ \\ ${ }^{1}$ Department of Biomedical Sciences, School of Basic and Biomedical Sciences, University of Health and Allied Sciences, Ho, Ghana \\ ${ }^{2}$ Department of Medical Laboratory Science, School of Biomedical and Allied Health Sciences, University of Ghana, Accra, Ghana \\ ${ }^{3}$ Department of Medical Microbiology, School of Biomedical and Allied Health Sciences, University of Ghana, Accra, Ghana
}

Correspondence should be addressed to Eric S. Donkor; ericsdon@hotmail.com

Received 24 May 2017; Accepted 1 August 2017; Published 6 September 2017

Academic Editor: Pierre Roques

Copyright (C) 2017 Kwabena O. Duedu et al. This is an open access article distributed under the Creative Commons Attribution License, which permits unrestricted use, distribution, and reproduction in any medium, provided the original work is properly cited.

\begin{abstract}
Enteric bacteria are commonly implicated in hospital-acquired or nosocomial infections. In Ghana, these infections constitute an important public health problem but little is known about their contribution to antibiotic resistance. The aim of the study was to determine the extent and pattern of antibiotic resistance of enteric bacteria isolated from patients and environmental sources at the Accra Psychiatric Hospital. A total of 265 samples were collected from the study site including 142 stool and 82 urine samples from patients, 7 swab samples of door handle, and 3 samples of drinking water. Enteric bacteria were isolated using standard microbiological methods. Antibiograms of the isolates were determined using the disc diffusion method. Overall, 232 enteric bacteria were isolated. Escherichia coli was the most common (38.3\%), followed by Proteus (19.8\%), Klebsiella (17.7\%), Citrobacter (14.7\%), Morganella (8.2\%), and Pseudomonas (1.3\%). All isolates were resistant to ampicillin but sensitive to cefotaxime. The resistance ranged from $15.5 \%$ to $84.5 \%$. Multidrug resistance was most prevalent (100\%) among isolates of Proteus and Morganella and least prevalent among isolates of Pseudomonas (33.3\%). Multidrug resistance among enteric bacteria at the study hospital is high and hence there is a need for screening before therapy to ensure prudent use of antibiotics.
\end{abstract}

\section{Introduction}

Psychiatric hospitals are specialized settings for the treatment of mental disorders. However, patients admitted in these hospitals are at a higher risk of acquiring nosocomial infections, which are the leading causes of death and increased morbidity for hospitalized patients [1-4]. In general, the sources of nosocomial infections can be categorized into environmental factors (such as the quality of water used at the hospital, inanimate objects, and architectural design), patient-related factors, iatrogenic factors (surgery and invasive procedures, devices and equipment, and antibiotic use), crowdedness at the hospital, and the hands of healthcare workers. Patients are at minimal risk if they have no significant underlying disease, have an intact immune system, and have not undergone any invasive procedure. High risk is assigned to patients who are susceptible to disease for a variety of reasons, including decreased immune function, low nutritional status, and mental disorders $[5,6]$.

Enteric bacterial pathogens are commonly implicated in nosocomial infections, particularly in environments where poor hygiene prevails $[2,4]$. These organisms can live on inanimate surfaces for as long as seven days to several months in the hospital environment $[7,8]$. They can also contaminate the drinking water and food of patients in the hospital [9, 10]. There is evidence that some insects, particularly cockroaches, could serve as vectors for dissemination of enteric pathogens in the hospital environment [11-13]. The common enteric bacterial pathogens implicated in nosocomial infections include Escherichia coli, Pseudomonas, Klebsiella, and Salmonella $[2,4]$.

Though antibiotic drugs have reduced the burden of common bacterial diseases and become essential for many medical interventions [14]; in recent times pathogens have 
become resistant to such drugs at an alarming rate. Drug resistant bacteria have been reported to cause about $20-70 \%$ of nosocomial infections [15]. The inappropriate use of antibiotics is a major contributor to the increase in drug resistant strains of bacteria, and, coupled with the natural selection and exchange of genetic resistance elements among microorganisms, drug resistance has emerged as a worldwide problem $[16,17]$. Multidrug resistant strains of enteric bacteria such as Salmonella, Acinetobacter, and Pseudomonas have been implicated in outbreaks in both developed and developing countries $[18,19]$. Though a global problem, drug resistance in bacteria poses a greater threat in the developing world where morbidity of bacterial diseases is much higher and treatment options are limited [20-22].

In Ghana, nosocomial infections constitute an important public health problem but little is known about these infections in relation to antibiotic resistance. The few studies on antibiotic resistance of nosocomial pathogens in Ghana seemed to have focused on a few causative organisms particularly Staphylococcus aureus [23-26], and there is hardly any data on enteric organisms. Additionally, previous studies on nosocomial infections in Ghana and many countries have focused on general hospital wards, and there is no data on special wards such as psychiatric hospitals. In Ghana, psychiatric wards are generally characterized by poor sanitary conditions; coupled with overcrowding and other factors, enteric organisms could be readily disseminated in the environment of these wards. The risk of enteric organisms in psychiatric wards in Ghana highlights the need for the current study, which was aimed at determining the extent and pattern of antibiotic resistance of enteric bacteria isolated from patients and environmental sources in a Ghanaian psychiatric hospital.

\section{Materials and Methods}

2.1. Study Area and Sampling. The study involved convenience sampling of patients and the environment at the Accra Psychiatric Hospital located in Accra (capital city of Ghana) from January to June, 2012. The hospital is a leading mental health facility serving the city of Accra, its environs, and the entire southern section of Ghana. Two hundred (200) inmates were randomly selected at the Accra Psychiatric Hospital wards, namely, the Special Ward, Wards $\mathrm{Cl}$ and $\mathrm{C} 2$, the Male Admission Ward, the Bank for Housing and Construction (BHC) Ward, the Male Infirmary Ward, the female Geriatric Ward, and the Female Infirmary Ward. Apart from hospitalisation for psychiatric reasons, the study participants were apparently healthy. Stool and/or urine samples were collected aseptically from the study participants who consented to provide the samples. Their drinking water sources were also sampled, while swabs samples were collected from door handles in the hospital wards. Overall, 265 samples were collected including 142 stool samples, 82 urine samples, 7 swab samples of door handle, and 3 samples of drinking water. The samples collected were transported immediately to the Bacteriology Laboratory of the School of Biomedical and Allied Health Sciences of University of Ghana for analysis.

\subsection{Laboratory Analysis}

2.2.1. Isolation and Identification of Bacteria. Stool samples were inoculated in Selenite F broth and subcultured onto deoxycholate agar. Urine samples were inoculated on Cysteine Lactose Electrolyte Deficient agar. Swab and water samples were inoculated on blood agar and MacConkey agar. The inoculated bacteriological media were incubated between 18 and 24 hours at $37^{\circ} \mathrm{C}$. Bacterial isolates were identified based on colonial morphology, Gram stain, and a battery of biochemical tests.

2.2.2. Antimicrobial Susceptibility Test. Antimicrobial susceptibility tests of bacterial isolates were done by the disc diffusion method according to the European Committee on Antimicrobial Susceptibility Testing (EUCAST) standards [27]. A minimum of four to five pure colonies of the test organism from an overnight growth was transferred into peptone water and the suspension was adjusted to a density of 0.5 McFarland turbidity standard. Optimally, within 15 minutes after adjusting the turbidity of the inoculum suspension, a sterile cotton swab was dipped into the adjusted suspension. The swab was rotated several times and pressed firmly on the inside wall of the tube above the fluid level to remove excess inoculum from the swab. The dried surface of a MuellerHinton agar plate was inoculated by streaking the swab over the entire sterile agar surface. This procedure was repeated by streaking two more times, rotating the plate approximately $60^{\circ}$ each time to ensure an even distribution of inoculum. The lid of the agar plate was left ajar for 3 to 5 minutes, but no more than 15 minutes, to allow for any excess surface moisture to be absorbed before applying the drug impregnated disks.

Antimicrobial discs of $10 \mu \mathrm{g}$ ampicillin, $30 \mu \mathrm{g}$ tetracycline, $10 \mu \mathrm{g}$ gentamicin, $30 \mu \mathrm{g}$ cefuroxime, $30 \mu \mathrm{g}$ chloramphenicol, $30 \mu \mathrm{g}$ cefotaxime, $30 \mu \mathrm{g}$ tetracycline, $30 \mu \mathrm{g}$ amikacin, and $25 \mu \mathrm{g}$ of cotrimoxazole were applied firmly to the surface of the inoculated agar plate. Urine antimicrobial discs were also used for the bacterial isolates from the urine samples. Within 15 minutes after the discs were applied, the plates were inverted and incubated aerobically at a temperature of $35^{\circ} \mathrm{C}$ for $18-24 \mathrm{hrs}$. Quality control testing was done by using Escherichia coli ATCC25922 strain for validation of the susceptibility testing process. Zone diameters around the antibiotic discs were measured and classified as sensitive or resistant based on the EUCAST break point system [27].

2.3. Data Analysis. Data were analyzed using the IBM SPSS Statistics version 23 (IBM Corporation, Armonk, NY). Descriptive analysis including frequencies and percentages (prevalence) was computed for the various enteric bacteria isolated from the specimens. Prevalence of an enteric bacterial organism was computed as a proportion of the total number of enteric isolates. Analyses of frequencies and percentages were done for resistant and multidrug resistance isolates. Multidrug resistance was defined as resistance to three or more classes of antimicrobial agents. 
TABLE 1: Enteric bacterial organisms isolated from various specimens at the Accra Psychiatric Hospital.

\begin{tabular}{|c|c|c|c|c|c|}
\hline \multirow{2}{*}{$\begin{array}{l}\text { Enteric } \\
\text { organism }\end{array}$} & \multicolumn{4}{|c|}{ Type of specimen } & \multirow{2}{*}{$\begin{array}{c}\text { Total isolates } \\
n(\%)\end{array}$} \\
\hline & $\begin{array}{l}\text { Stool } \\
n(\%)\end{array}$ & $\begin{array}{l}\text { Urine } \\
n(\%)\end{array}$ & $\begin{array}{c}\text { Door handle } \\
n(\%)\end{array}$ & $\begin{array}{l}\text { Water } \\
n(\%)\end{array}$ & \\
\hline E. coli & $36(25.4)$ & $48(58.6)$ & $2(40.0)$ & $3(100.0)$ & $89(38.3)$ \\
\hline Proteus & $29(20.4)$ & $17(20.7)$ & $0(0.0)$ & $0(0.0)$ & $46(19.8)$ \\
\hline Klebsiella & $24(16.9)$ & $17(20.7)$ & $0(0.0)$ & $0(0.0)$ & $41(17.7)$ \\
\hline Citrobacter & $34(23.9)$ & $0(0.0)$ & $0(0.0)$ & $0(0.0)$ & $34(14.7)$ \\
\hline Morganella & $19(13.4)$ & $0(0.0)$ & $0(0.0)$ & $0(0.0)$ & $19(8.2)$ \\
\hline Pseudomonas & $0(0.0)$ & $0(0.0)$ & $3(60.0)$ & $0(0.0)$ & $3(1.3)$ \\
\hline Total isolates & $142(100.0)$ & $82(100.0)$ & $5(100.0)$ & $3(100.0)$ & $232(100.0)$ \\
\hline
\end{tabular}

Number outside parentheses indicates number of individual isolates $(n)$; number in parentheses indicates the corresponding proportion of isolates in percent (\%).

\section{Results}

Overall, 237 (88.5\%) of the 265 samples collected were culture positive and the enteric bacteria isolated are shown in Table 1. Escherichia coli was isolated from all the specimen types and was most prevalent in urine (58.6\%). Proteus and Klebsiella were isolated from only urine and stool samples; Proteus had similar prevalence in stool (20.4\%) and urine (20.7\%), while Klebsiella was more prevalent in urine (20.7\%). Citrobacter and Morganella were isolated from only stool specimens with prevalence of $23.9 \%$ and $13.4 \%$, respectively. Pseudomonas was isolated from only door handles at a prevalence of $60 \%$. Overall, E. coli was the most common organism isolated (38.3\%), followed by Proteus (19.8\%), Klebsiella (17.7\%), Citrobacter (14.7\%), Morganella (8.2\%), and Pseudomonas (1.3\%).

Antimicrobial susceptibility testing results of the various enteric bacteria isolated are shown in Figure 1. All isolates were resistant to ampicillin and tetracycline except for Klebsiella where only $52 \%$ were resistant to tetracycline. Various degrees of resistance were observed for chloramphenicol for all the isolates with the exception of Proteus. The E. coli isolates were resistant to ampicillin and tetracycline but sensitive to cefotaxime. High E. coli resistance was also observed for chloramphenicol (83.3\%) and cotrimoxazole (66.7\%). All the Proteus isolates were resistant to ampicillin, tetracycline, and cotrimoxazole but sensitive to chloramphenicol, gentamycin, cefuroxime, and cotrimoxazole. All the Klebsiella isolates were resistant to ampicillin but sensitive to gentamycin, cefuroxime, cefotaxime, and amikacin; high percentage resistance of Klebsiella was also observed for tetracycline (52.38\%) and cotrimoxazole (84.45\%). All the Citrobacter isolates were sensitive to the antibiotics tested except chloramphenicol, ampicillin, and tetracycline, which had percentage resistance of $34.8 \%, 100 \%$, and $100 \%$, respectively. Overall, all the isolates tested were resistant to ampicillin but sensitive to cefotaxime. As shown in Table 2, multidrug resistance was most prevalent among isolates of Proteus (100\%) and Morganella (100\%) and least prevalent among isolates of Pseudomonas $(33.3 \%)$.
TABLE 2: Prevalence of multidrug resistant isolates among enteric bacterial organisms at the Accra Psychiatric Hospital.

\begin{tabular}{lcc}
\hline Enteric bacterial organism & $n$ & $\%$ \\
\hline Proteus & 46 & 100 \\
Morganella & 19 & 100 \\
Escherichia coli & 74 & 83.3 \\
Klebsiella & 21 & 51.2 \\
Citrobacter & 11 & 33.4 \\
Pseudomonas & 1 & 33.3 \\
\hline
\end{tabular}

\section{Discussion}

In this study, antibiotic resistance among enteric bacteria at a psychiatric hospital in Ghana was investigated. The patterns of antibiotic resistance of the various enteric bacteria were similar for six of the eight drugs tested including ampicillin, tetracycline, gentamicin, cefuroxime, cefotaxime, and amikacin. This may be due to the similarity of structural and genetic resistance properties that are shared by this family of bacteria. The presence of an outer membrane in enteric bacteria (Gram negative bacteria) generally excludes antibiotics from penetrating the cell [28]. Additionally, these organisms have a great facility for exchanging genetic material (DNA) among strains of the same species and even among different species [29].

Extremely high percentage resistance to ampicillin and tetracycline was observed, which concurs with previous studies on enteric organisms in Ghana [30,31]. In enteric organisms, tetracycline resistance is mediated by tet (A) and tet (B) genes that encode efflux proteins. Resistance to ampicillin and other beta-lactam drugs in these organisms is mediated by $\beta$-lactamases. The introduction of new $\beta$ lactams with different activity spectra has led to a selection of different genes and mutations that confer resistance to these drugs in enteric bacteria [23, 32]. Epidemiological evidence suggests that the increasing resistance prevalence of tetracycline, ampicillin, and many other antibiotics is directly 


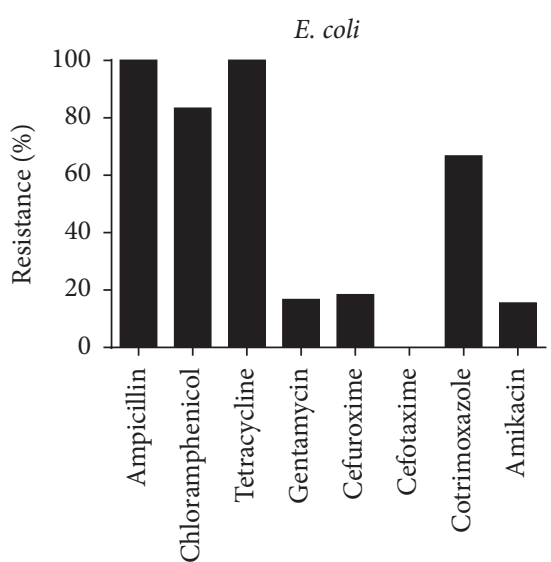

Antibiotics

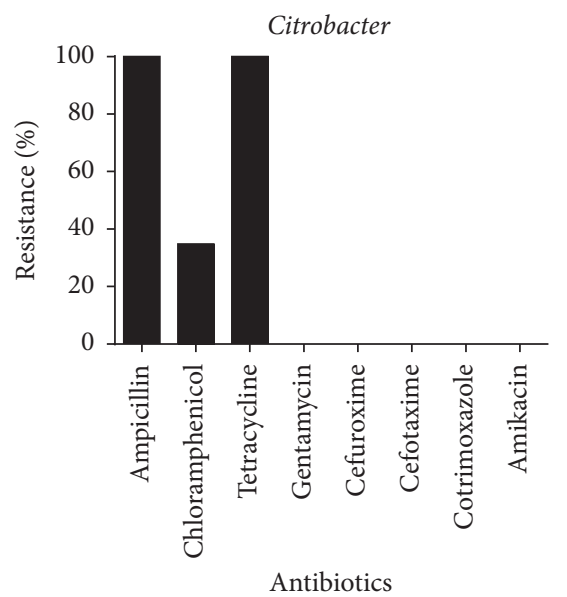

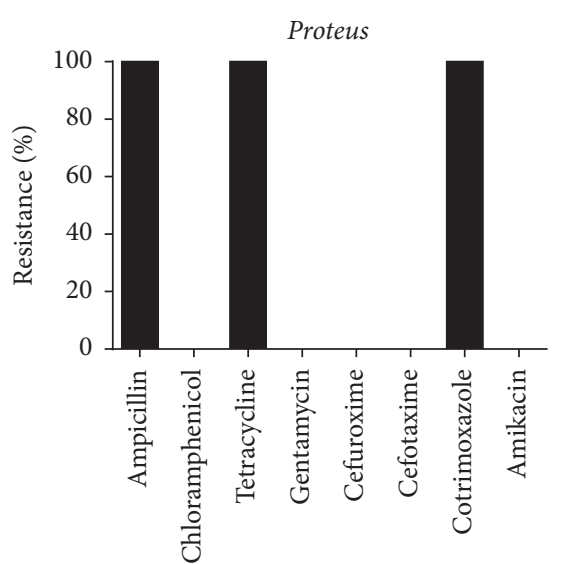

Antibiotics

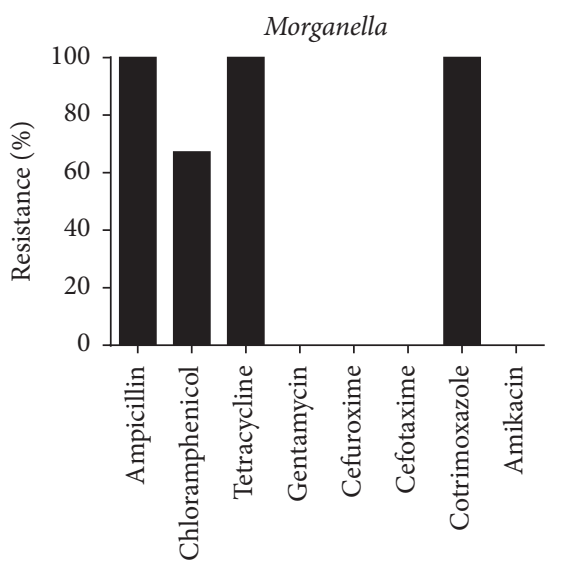

Antibiotics

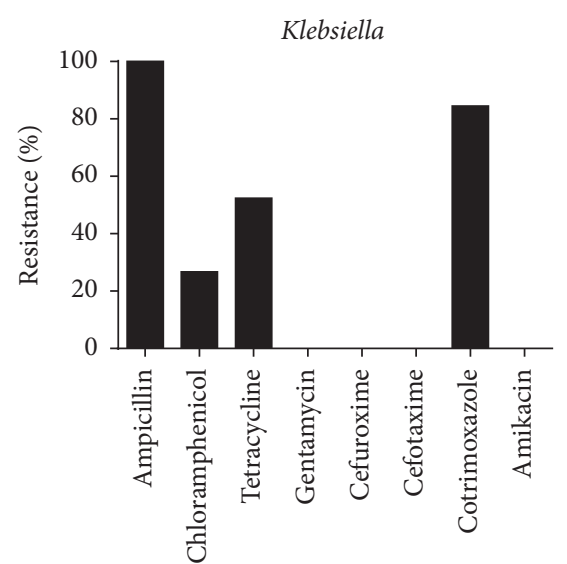

Antibiotics

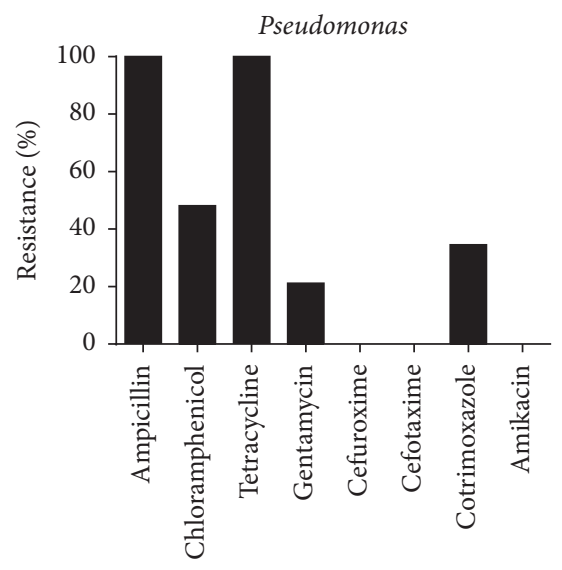

Antibiotics

Figure 1: Antibiogram of six enteric bacterial organisms isolated at the Accra Psychiatric Hospital.

linked to their usage. In Ghana, tetracycline and ampicillin have been on the market for a very long time; this, coupled with the high rates of self-medication in the country [30, 31], contributes significantly to the high bacterial resistance observed in this study. The lower prevalence of resistance observed for cefuroxime, cefotaxime, and amikacin in this study is probably because these antibiotics have been on the market for relatively shorter period and may not have been subjected to high usage like ampicillin and tetracycline. In addition, some of these drugs such as cefotaxime are expensive and this tends to limit their usage in Ghana where the incomes of many people are still low.

The data of this study suggests that multidrug resistance may be widespread among enteric bacterial organisms in Ghana. This is not surprising, as enteric bacteria tend to be associated with mobile genetic elements such as plasmids and transposons, which usually carry multiple resistance genes [33]. The enteric organisms investigated in this study have been implicated in various nosocomial infections, and their high levels of resistance have important implications for treatment of such infections in the study setting. For example, E. coli, which showed multidrug resistance prevalence of $83.3 \%$, is a leading cause of nosocomial urinary tract infection [34-36]. Similarly, Klebsiella, which is a common cause of blood stream infections in the hospital setting [37-39], showed high multidrug resistance prevalence of $51.2 \%$. In Ghana, antibiotic treatment options are relatively limited and, therefore, the high prevalence of multidrug resistance observed could have a significant impact on public health. The gut is the main source of enteric bacteria and therefore the risk of dissemination of multidrug resistance enteric bacteria from this source is probably high. The key risk factors for dissemination include dependency for toileting, diarrhea, and living in countries where hygiene is poor [40-42]. Consequently, the very low compliance with hand hygiene rules in most hospitals in the developing world is a major obstacle to preventing the cross-transmission of multiresistant enteric bacteria.

\section{Conclusion}

This study concludes that multidrug resistance is highly prevalent among enteric bacterial organisms in the study hospital. This probably reflects the trend in other hospitals in Ghana. The study has exposed an important public health problem regarding antibiotic resistance of enteric bacteria related to the hospital environment. Two recommendations to begin to address this problem are (a) creation of more awareness among clinicians and other healthcare professionals of the potential interventions, (b) surveillance of 
antibiotic resistance among enteric pathogens, and (c) further research to more clearly define the problem and how it can be addressed. In particular, there is the need to use molecular methods to further investigate antibiotic resistance of enteric pathogens.

\section{Conflicts of Interest}

The authors declare no conflicts of interest.

\section{Authors' Contributions}

Kwabena O. Duedu, Eric S. Donkor, and Francis S. Codjoe conceived and designed the study. George Offei and Kwabena O. Duedu recruited the study subjects, collected specimens, and carried out laboratory analysis. Kwabena O. Duedu, Eric S. Donkor, George Offei, and Francis S. Codjoe carried out data analyses and raised arguments for the paper. Eric S. Donkor, Kwabena O. Duedu, and George Offei wrote the manuscript. Francis S. Codjoe conducted critical review of the manuscript.

\section{Acknowledgments}

The authors thank the study participants for providing specimens for the study. Technical assistance provided by Rachael Mills and Samuel Gyasi Asare of the Central Laboratory, Korle Bu Teaching Hospital, is gratefully acknowledged.

\section{References}

[1] H. A. Khan, A. Ahmad, and R. Mehboob, "Nosocomial infections and their control strategies," Asian Pacific Journal of Tropical Biomedicine, vol. 5, no. 7, pp. 509-514, 2015.

[2] X.-B. Tao, L.-H. Qian, Y. Li et al., "Hospital-acquired infection rate in a tertiary care teaching hospital in China: a cross-sectional survey involving 2434 inpatients," International Journal of Infectious Diseases, vol. 27, pp. e7-e9, 2014.

[3] L. Raka, D. Zoutman, G. Mulliqi et al., "Prevalence of nosocomial infections in high-risk units in the University Clinical Center of Kosova," Infection Control and Hospital Epidemiology, vol. 27, no. 4, pp. 421-423, 2006.

[4] E. R. M. Sydnor and T. M. Perl, "Hospital epidemiology and infection control in acute-care settings," Clinical Microbiology Reviews, vol. 24, no. 1, pp. 141-173, 2011.

[5] World Health Organization, Prevention of Hospital-Acquired Infections. A Practical Guide, World Health Organization, Geneva, Switzerland, 2nd edition, 2002.

[6] A. N. Kieninger and P. A. Lipsett, "Hospital-acquired pneumonia: pathophysiology, diagnosis, and treatment," Surgical Clinics of North America, vol. 89, no. 2, pp. 439-461, 2009.

[7] A. C. de Oliveira and Q. S. Damasceno, "Surfaces of the hospital environment as possible deposits of resistant bacteria: a review," Revista da Escola de Enfermagem, vol. 44, no. 4, pp. 1118-1123, 2010.

[8] M. K. Hayden, D. W. Blom, E. A. Lyle, C. G. Moore, and R. A. Weinstein, "Risk of hand or glove contamination after contact with patients colonized with vancomycin-resistant Enterococcus or the colonized patients' environment," Infection Control and Hospital Epidemiology, vol. 29, no. 2, pp. 149-154, 2008.
[9] T. Felfoldi, Z. Heéger, M. Vargha, and K. Márialigeti, "Detection of potentially pathogenic bacteria in the drinking water distribution system of a hospital in Hungary," Clinical Microbiology and Infection, vol. 16, no. 1, pp. 89-92, 2010.

[10] J. Falkinham, A. Pruden, and M. Edwards, "Opportunistic premise plumbing pathogens: increasingly important pathogens in drinking water," Pathogens, vol. 4, no. 2, pp. 373-386, 2015.

[11] P. B. Tetteh-Quarcoo, S. E. Donkor, K. S. Attah et al., "Microbial carriage of cockroaches at a tertiary care hospital in ghana," Environmental Health Insights, vol. 7, pp. 59-66, 2013.

[12] A. Salehzadeh, P. Tavacol, and H. Mahjub, "Bacterial, fungal and parasitic contamination of cockroaches in public hospitals of Hamadan, Iran," Journal of Vector Borne Diseases, vol. 44, no. 2, pp. 105-110, 2007.

[13] U. Ilker, S. Hugo, P. Sandrine Longet Di et al., "Cockroaches (Ectobius vittiventris) in an Intensive Care Unit, Switzerland," Emerging Infectious Diseases, vol. 15, no. 3, pp. 496-497, 2009.

[14] T. P. Van Boeckel, S. Gandra, A. Ashok et al., "Global antibiotic consumption 2000 to 2010: an analysis of national pharmaceutical sales data," The Lancet Infectious Diseases, vol. 14, no. 8, pp. 742-750, 2014.

[15] N. Brusselaers, D. Vogelaers, and S. Blot, "The rising problem of antimicrobial resistance in the intensive care unit," Annals of Intensive Care, vol. 1, no. 1, p. 47, 2011.

[16] P. J. Van Duijn, M. J. D. Dautzenberg, and E. A. N. Oostdijk, "Recent trends in antibiotic resistance in European ICUs," Current Opinion in Critical Care, vol. 17, no. 6, pp. 658-665, 2011.

[17] L. C. McDonald, "Trends in antimicrobial resistance in health care-associated pathogens and effect on treatment," Clinical Infectious Diseases, vol. 42, no. 2, pp. S65-S71, 2006.

[18] P. Scott, G. Deye, A. Srinivasan et al., "An outbreak of multidrug-resistant Acinetobacter baumannii-calcoaceticus complex infection in the US military health care system associated with military operations in Iraq," Clinical Infectious Diseases, vol. 44, no. 12, pp. 1577-1584, 2007.

[19] U. Gross, S. K. Amuzu, R. de Ciman et al., "Bacteremia and antimicrobial drug resistance over time, Ghana," Emerging Infectious Diseases, vol. 17, no. 10, pp. 1879-1882, 2011.

[20] I. M. Gould and A. M. Bal, "New antibiotic agents in the pipeline and how hey can help overcome microbial resistance," Virulence, vol. 4, no. 2, pp. 185-191, 2013.

[21] G. M. Rossolini, F. Arena, P. Pecile, and S. Pollini, "Update on the antibiotic resistance crisis," Current Opinion in Pharmacology, vol. 18, pp. 56-60, 2014.

[22] C. L. Ventola, "The antibiotic resistance crisis-part 1: causes and threats," Pharmacy and Therapeutics, vol. 40, no. 4, pp. 277283, 2015.

[23] N. Obeng-Nkrumah, K. Twum-Danso, K. A. Krogfelt, and M. J. Newman, "High levels of extended-spectrum beta-lactamases in a major teaching hospital in Ghana: the need for regular monitoring and evaluation of antibiotic resistance," American Journal of Tropical Medicine and Hygiene, vol. 89, no. 5, pp. 960964, 2013.

[24] D. F. George, S. Y. Gbedema, C. Agyare et al., "Antibiotic Resistance Patterns of Escherichia coli Isolates from Hospitals in Kumasi, Ghana," ISRN Microbiology, vol. 2012, pp. 1-5, 2012.

[25] S. J. Leopold, F. van Leth, H. Tarekegn, and C. Schultsz, "Antimicrobial drug resistance among clinically relevant bacterial isolates in sub-Saharan Africa: a systematic review," Journal of Antimicrobial Chemotherapy, vol. 69, no. 9, Article ID dkul76, pp. 2337-2353, 2014. 
[26] S. B. B. M. Saana, F. Adu, C. Agyare, S. Y. Gbedema et al., "Antibiotic resistance patterns of strains of Staphylococcus aureus isolated from patients in three hospitals in Kumasi, Ghana," Journal of Bacteriology Research, vol. 5, no. 3, pp. 35-40, 2013.

[27] EUCAST, 2015. Antimicrobial susceptibility testing: EUCAST disk diffusion method. European Committee for Antimicrobial Susceptibility Testing. Version 5.0.

[28] T. J. Silhavy, D. Kahne, and S. Walker, "The bacterial cell envelope," Cold Spring Harbor Perspectives in Biology, vol. 2, no. 5, Article ID a000414, 2010.

[29] R. I. Aminov, "Horizontal gene exchange in environmental microbiota," Frontiers in Microbiology, vol. 2, 158 pages, 2011.

[30] M. J. Newman, E. Frimpong, E. S. Donkor, J. A. Opintan, and A. Asamoah-Adu, "Resistance to antimicrobial drugs in Ghana," Infection and Drug Resistance, vol. 4, no. 1, pp. 215-220, 2011.

[31] J. A. Opintan, M. J. Newman, R. E. Arhin, E. S. Donkor, M. Gyansa-Lutterodt, and W. Mills-Pappoe, "Laboratory-based nationwide surveillance of antimicrobial resistance in Ghana," Infection and Drug Resistance, vol. 8, pp. 379-389, 2015.

[32] D. Eibach, C. B. Campos, R. Krumkamp et al., "Extended spectrum beta-lactamase producing Enterobacteriaceae causing bloodstream infections in rural Ghana, 2007-2012," International Journal of Medical Microbiology, vol. 306, no. 4, pp. 249254, 2016.

[33] K. A. Abdel Rahim, A. M. Hassanein, and H. A. Abd El Azeiz, "Prevalence, plasmids and antibiotic resistance correlation of enteric bacteria in different drinking water resources in sohag, egypt," Jundishapur Journal of Microbiology, vol. 8, no. 1, 2015.

[34] O. Akingbade, S. Balogun, D. Ojo et al., "Resistant plasmid profile analysis of multidrug resistant Escherichia coli isolated from urinary tract infections in Abeokuta, Nigeria," African Health Sciences, vol. 14, no. 4, pp. 821-828, 2014.

[35] S. L. Chen, M. Wu, J. P. Henderson et al., "Genomic diversity and fitness of E. coli strains recovered from the intestinal and urinary tracts of women with recurrent urinary tract infection," Science Translational Medicine, vol. 5, no. 184, 2013.

[36] F. Toval, C.-D. Köhler, U. Vogel et al., "Characterization of Escherichia coli isolates from hospital inpatients or outpatients with urinary tract infection," Journal of Clinical Microbiology, vol. 52, no. 2, pp. 407-418, 2014.

[37] M. Tumbarello, T. Spanu, M. Sanguinetti et al., "Bloodstream infections caused by extended-spectrum- $\beta$-lactamaseproducing Klebsiella pneumoniae: risk factors, molecular epidemiology, and clinical outcome," Antimicrobial Agents and Chemotherapy, vol. 50, no. 2, pp. 498-504, 2006.

[38] E. Szilagyi, M. Füzi, K. Böröcz, A. Kurcz, Á. Tóth, and K. Nagy, "Risk factors and outcomes for bloodstream infections with extended-spectrum $\beta$-lactamase-producing Klebsiella pneumoniae; Findings of the nosocomial surveillance system in Hungary," Acta Microbiologica et Immunologica Hungarica, vol. 56, no. 3, pp. 251-262, 2009.

[39] N. Girometti, R. E. Lewis, M. Giannella et al., "Klebsiella pneumoniae bloodstream infection epidemiology and impact of inappropriate empirical therapy," Medicine, vol. 93, no. 17, pp. 298-308, 2014.

[40] E. O. Oloruntoba, T. B. Folarin, and A. I. Ayede, "Hygiene and sanitation risk factors of Diarrhoeal disease among under-five children in Ibadan, Nigeria," African Health Sciences, vol. 14, no. 4, pp. 1001-1011, 2014.

[41] K. O. Duedu, Y. A. Karikari, S. K. Attah, and P. F. Ayeh-Kumi, "Prevalence of intestinal parasites among patients of a Ghanaian psychiatry hospital," BMC Research Notes, vol. 8, no. 1, article 651, 2015.

[42] K. Duedu, E. Peprah, I. Anim-Baidoo, and P. F. Ayeh-Kumi, "Prevalence of intestinal parasites and association with malnutrition at a ghanaian orphanage," Human Parasitic Diseases, vol. 7, pp. 5-9, 2015. 

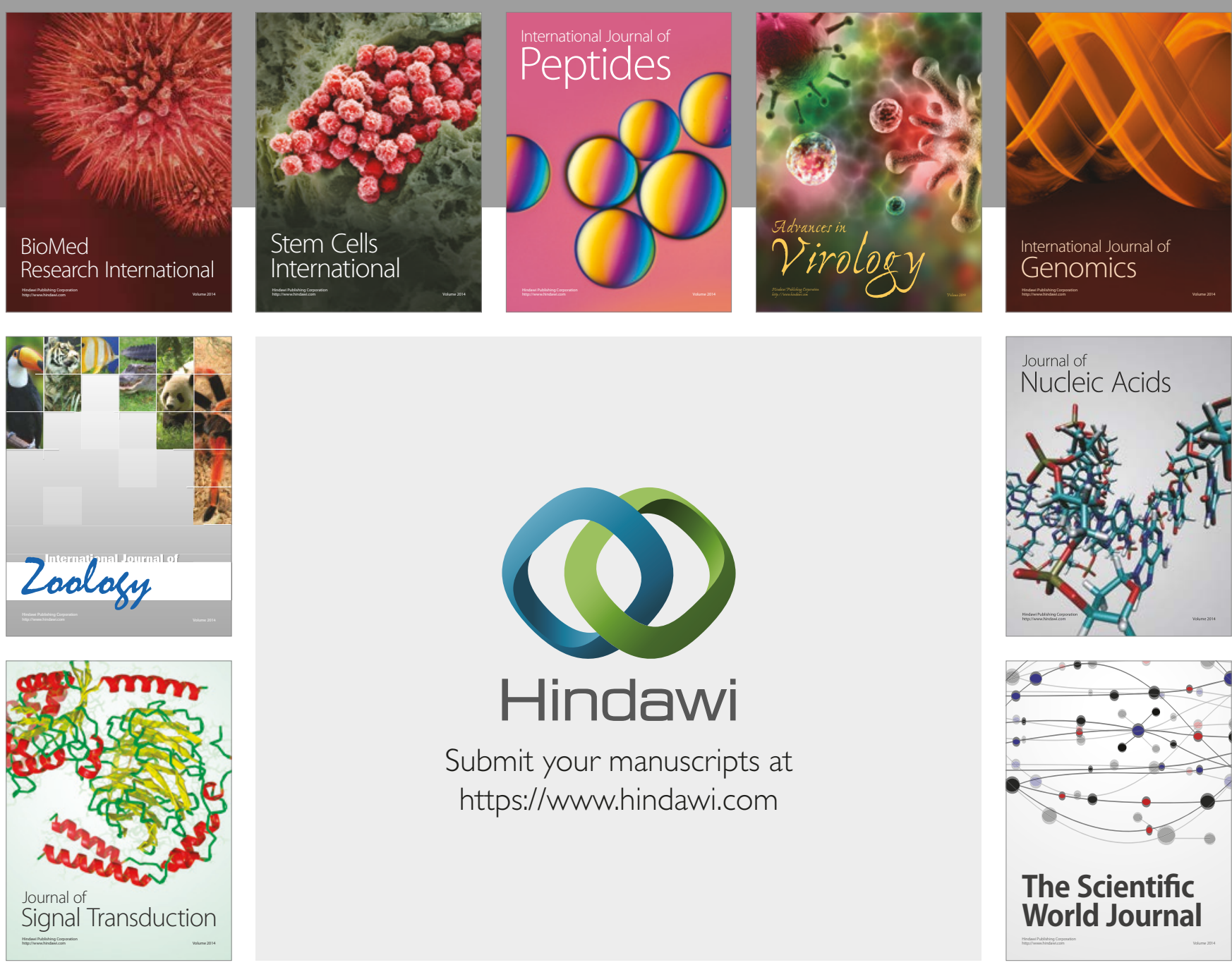

Submit your manuscripts at

https://www.hindawi.com
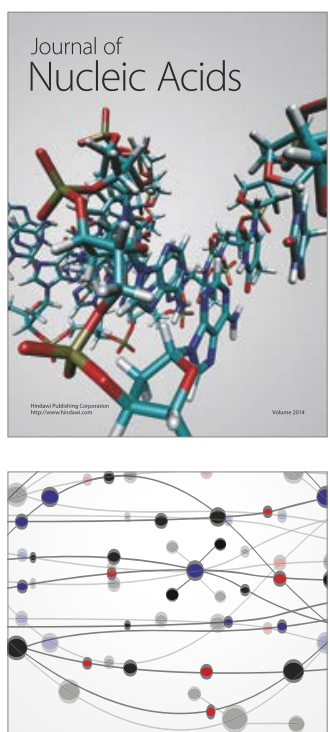

The Scientific World Journal

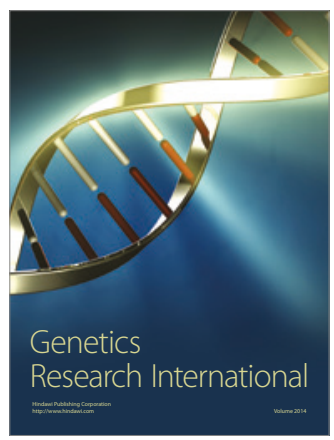

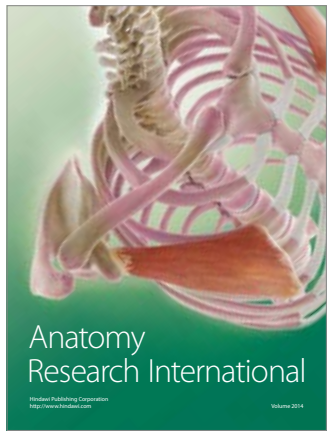

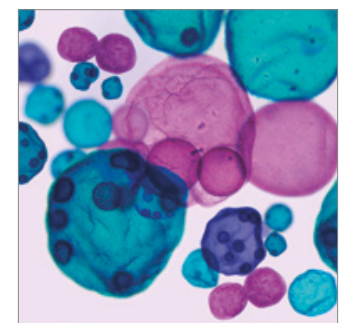

International Journal of Microbiology
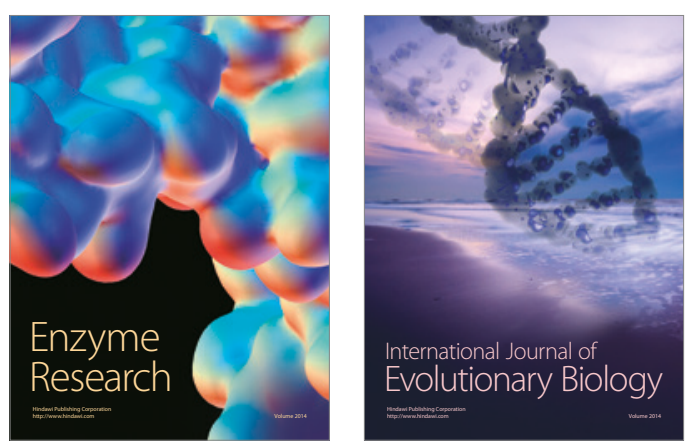
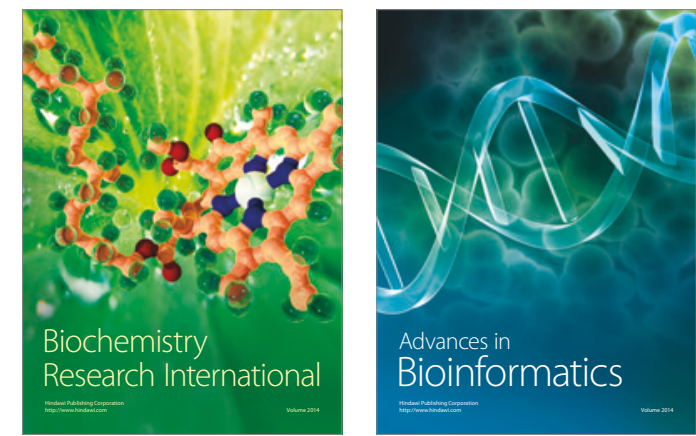

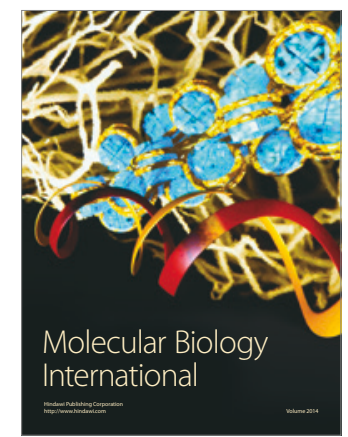

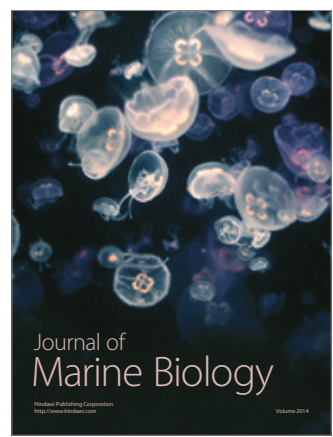

